the consensus view has indicated that the risk is slightly increased. Nevertheless, this view relates to the higher dose oral contraceptives and not to those currently used. There is no evidence that women who develop cardiovascular disease while using oral contraceptives are those whose metabolic responses are excessive. Nor is there any evidence suggesting a difference among different oral contraceptives in the incidence of cardiovascular disease. Some consider that oral contraceptives are not typical atherogenic risk factors at all'; occlusive coronary thrombosis may occur without appreciable atherogenic changes on angiography or histology of coronary vessels.

Metabolic changes occur in all women using oral contraceptives but few of them develop cardiovascular disease.
Nevertheless, it is sensible to follow general therapeutic principles by using formulations containing the lowest doses consistent with efficacy and acceptability.

K FOTHERBY

Reader Emeritus,

Royal Postgraduate Medical School,

Hammersmith Hospital,

London W12 0NN

Fotherby K. Oral contraceptives, lipids and cardiovascular disease. Contraception 1985;31:367-94 2 Fotherby K. Clinical pharmacology of gestagens. In: Runnebauum B, Rabe T, Kiesel L, eds. Female contraception. Berlin: Springer-Verlag, 1988:122-8.

colini JP, Goldzic JW Orag,

epidemiological studies. Am f Obstet Gynecol 1985;152:729-98. women; role of oral contraceptives. Eur Heart f 1983;4:1-8.

\title{
Non-insulin dependent diabetes and ischaemic heart disease
}

\author{
Related, but how?
}

Non-insulin dependent diabetics are at greater risk from ischaemic heart disease than the general population. ${ }^{12}$ This is not surprising: most metabolic abnormalities linked to vascular disease have been described in non-insulin dependent diabetics. These abnormalities include increased concentrations of glucose, insulin, and triglyceride and reduced concentrations of high density lipoprotein cholesterol. ${ }^{12}$ Noninsulin dependent diabetics are more likely to have abnormalities of platelet function ${ }^{3}$ and the coagulation system ${ }^{4}$ and to be hypertensive and overweight.

These risk factors, however, do not completely explain the increased risk of vascular disease in diabetics. Nor is there evidence that conventional risk factors are relatively more important in diabetics than non-diabetics; for example, smoking, hypertension, and hypercholesterolaemia increase the risk of ischaemic heart disease by similar amounts in both groups.

Further complicating the story are epidemiological studies showing that the effect of diabetes as a "multiplier" of the risk of ischaemic heart disease varies according to geography and gender. Diabetic men in east Finland, for example, are more than twice as likely to have ischaemic heart disease as diabetic men in south west Finland. ${ }^{5}$ Within the same population the excess risk of ischaemic heart disease due to diabetes seems higher in diabetic women than in diabetic men, ${ }^{12}$ which could be explained by the greater clustering of coronary risk factors in female than male diabetics. ${ }^{6}$

Recent research into the association between non-insulin dependent diabetes and ischaemic heart disease has concentrated on the interactions among various metabolic abnormalities in diabetes. Insulin has been shown to act like a growth factor on the arterial wall, promoting the infiltration of smooth muscle cells into the intima and their replication there. ${ }^{78}$ It may also affect the activity of low density lipoprotein receptors and the binding and degradation of low density lipoprotein in fibroblasts and other cells. Hyperinsulinaemia and insulin resistance are associated with hypertension and an atherogenic lipoprotein profile. Triglyceride rich lipoproteins are more atherogenic in diabetics than in non-diabetics. The formation of lipid peroxides is increased in diabetics ${ }^{90}$ : oxidised low density lipoprotein accelerates the accumulation of cholesterol within endothelial macrophages. It may also promote atherogenesis by its cytotoxic properties $^{11}$ and its stimulation of monocyte chemotaxis. ${ }^{12}$

On the basis of the Whitehall study, which followed up more than 17000 men for 15 years, Jarrett and Shipley have suggested that diabetes and ischaemic heart disease may not be causally linked at all but may share a common, possibly genetic, antecedent. ${ }^{131+}$ Their main evidence from the study was that the relative risk of death from ischaemic heart disease bore no relation to the duration of diabetes in both newly diagnosed and previously diagnosed diabetics.

Assessing the duration of diabetes retrospectively in a cross sectional survey may lead to bias for two reasons. The first is owing to sampling bias, which could also be called survival bias: subjects who have had diabetes for many years at the beginning of such a study are "survivors" and might have other characteristics protecting them from the increased risk that goes with increased duration of the disease. Possible protective characteristics, uncontrolled for in the analysis of the Whitehall study, relate to high density lipoprotein cholesterol concentration, coagulation factors, platelet function, dietary and physiological antioxidants, and relative weight. The second source of bias is that the duration of diabetes is dated from the diagnosis: a short history of diabetes may, however, have followed prolonged asymptomatic glucose intolerance. Short of following the glucose tolerance of a large birth cohort from adolescence onwards, circumventing this limitation is impossible.

Even if the findings of the Whitehall study are valid there are explanations for an association between non-insulin dependent diabetes and ischaemic heart disease other than a genetically linked predisposition. Both diseases could be linked, for example, through a third factor, such as obesity or low high density lipoprotein cholesterol concentration, neither of which the Whitehall study adjusted for.

Further epidemiological studies are needed before abandoning the concept that non-insulin dependent diabetes and ischaemic heart diseases are causally linked.

Professor of Epidemiology,

JUKKA T SALONEN

University of Kuopio,

70211 Kuopio, Finland

\footnotetext{
1 Pyörälä K, Laakso M, Uusitupa M. Diabetes and atherosclerosis: an epidemiologic view. Diabete Metab Rev 1987;3:463-524.

2 Stout R. Insulin and atheroma - an update. Lancet 1987; ;:1077-9.
} 
3 Colwell JA, Winocour PD, Lopes-Virella M, Halushka PV. New concepts about the pathogenesis of atherosclerosis in diabetes mellitus. Am $\mathcal{F}$ Med 1983;75:67-80.

4 Jones RL, Peterson CM. Hematologic alterations in diabetes mellitus. Am $\mathcal{F}$ Med 1981;70:339-52.

5 Laakso M, Rönnemaa T, Pyörälä K, Kallio V, Puukka P, Penttilä I. Atherosclerotic vascula disease and its risk factors in non-insulin-dependent diabetic and nondiabetic subjects in Finland. Diabetes Care 1988;11:449-63.

6 Wingard DL, Barrett-Connor E, Criqui MH, Suarez $\mathrm{L}$. Clustering of heart disease risk factors in diabetic compared to nondiabetic adults. Am $\mathcal{F}$ Epidemiol 1983;117:19-26.

Stout RW, Bierman EL, Ross R. Effect of insulin on the proliferation of cultured primate arterial smooth muscle cells. Circulation Res 1987;36:319-27.

8 Nakao J, Ito H, Kanayasu T, Murota S-I. Stimulatory effect of insulin on aortic smooth muscle cell migration induced by $12-\mathrm{L}$-hydroxy-5, $8,10,14$-eicosatetraenoic acid and its modulation by

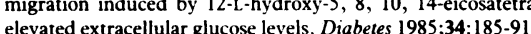

$9 \mathrm{Kaji} \mathrm{H}$, Kurasaki $M$, Ito $\mathrm{K}$, et al. Increased lipoperoxide value and glutathione peroxidase activity in blood plasma of type 2 (non-insulin-dependent) diabetic women. Klin Wochenschr 1985;63: $765-8$.

10 Bodnar PN, Donish RM, Pristupiuk AM. Interrelation of diabetes mellitus, atherosclerosis and ischemic heart disease. Ter Arkh 1984;56:88-92.

11 Hessler JR, Morel DW, Lewis J, Chisolm GM. Lipoprotein oxidation and lipoprotein-induced cytotoxicity. Arteriosclerosis 1983;3:215-72.

12 Quinn MT, Parthasarathy S, Fong LG, Steinberg D. Oxidatively modified low density lipoproteins: a potential role in recruitments and retention of monocyte/macrophages during atherogenesis. Proc Natl Acad Sci USA 1987;84:2995-8.

13 Jarrett RJ. Type 2 (non-insulin-dependent) diabetes mellitus and coronary heart disease-chicken, egg or neither. Diabetologia 1984;26:99-102.

14 Jarrett RJ, Shipley MJ. Type 2 (non-insulin-dependent) diabetes mellitus and cardiovascular disease-putative association via common antecedents; further evidence from the Whitehall study. Diabetologia 1988;31:737-40.

\section{A core medical curriculum}

\section{Two recent reports presage changes in medical education}

The education committee of the General Medical Council (GMC) has recently quietly reviewed the teaching of the clinical and diagnostic disciplines in British medical schools.' Some of the details of the council's report are curiously consonant with the "Edinburgh declaration" from the world conference on medical education despite the Edinburgh report reading somewhat like an educational revelation from St John the Divine (Report of the world conference on medical education, Edinburgh, 1988). Yet the Edinburgh conference was in little doubt that medical education is up a gum tree whereas the GMC report concludes that "there is a vigour in the pursuit of the delivery of medical education, and a diversity of opportunity that is impressive" and that "the council's recommendations on basic medical education are everywhere being followed." Reading between the lines we detect concerns at the GMC about the state of British medical education.

Surprisingly, the council's report shows considerable differences among schools in the form of their clinical courses. The length of surgical clerkships (and its specialties) ranges from 13 to 36 weeks; the size of teaching groups in psychiatry ward rounds varies from one to 14 studentş; students may spend from six to 50 weeks doing clinical work away from the main teaching centres; and in two schools about 90 necropsies are seen by students whereas in another they are "probably" not attended at all by many students. Eight schools provide no patient contact in the preclinical period, and three schools have no curriculum committee. Student research is little encouraged; the taking of intercalated degrees is often dependent on personal finance, and the degrees are rarely taken in clinical departments. The separation of pathology from clinical teaching is seen as possibly impairing an understanding of their interrelations. The "second $\mathrm{MB}$ barrier" still exists in most schools, and with the exception of those from departments of psychology and sociology few preclinical teachers contribute to the clinical teaching. Finally, although schools accept the importance of teaching communication skills, many provide no formal teaching and have not identified ways of doing so or assessing communication skills. Overall the curriculum is seen as "already overcrowded," with exposure to some subjects being so brief as perhaps to be without benefit. The possibility thus arises of the education committee stipulating a "core course with options."

The Edinburgh declaration specifies 24 steps for an "international collaborative programme for re-orientation of medical education." Despite-or perhaps because of - the revolutionary and idealistic sentiments of the Edinburgh report the likelihood of a radical change in undergraduate medical education in Britain seems remote in the short term. Resources are too restricted, and the apparatus of medical education contains too much friction and inertia. But if such a revolution is to occur then it may well come from the GMC's own education committee, which has for many years succoured and supported the institutionally unfashionable and underresourced subjects of behavioural sciences, community medicine, and general practice. ${ }^{2}$ The education committee may well find many of its sentiments set out within the Edinburgh declaration. Thus under "competence in individual diagnosis and management" the report states:

"Students have to learn to listen to patients attentively, to look at them with the intensity of the trained observer, and to communicate well with patients, relatives, and other health professionals. They must also learn to prevent and treat common disorders, to keep clear the accurate records, to handle common emergencies and also about rehabilitation. They must learn to recognise when they must seek help from others."

The action needed to achieve such a goal is to "define the essential core of knowledge and professional competence which is required ..." (our emphasis). The definition of a core curriculum, previously advocated by students themselves, ${ }^{3}$ is now technically feasible with methods such as the critical incident technique in which thousands of real medical events are analysed to determine the skills needed to do the job. ${ }^{4}$ Core syllabuses in each subject - perhaps determined by consensus conferences organised by the GMC - would not only reduce curriculum overloading but also might help to shift the educational emphasis away from being taught towards actively learning.

Senior Lecturer in Psychology Applied to Medicine,

I C MCMANUS

St Mary's Hospital Medical School,

London W2 $1 \mathrm{NY}$

Senior Research Associate,

R E WAKEFORD

Office of the Regius Professor of Physic,

Cambridge University School of Clinical Medicine,

Cambridge CB2 2QQ

1 General Medical Council Education Committee. Report of a survey of medical education practices in United Kingdom medical schools. London: General Medical Council, 1988.

2 General Medical Council Education Committee. Report of a working party on the teaching of behavioural science, community medicine and general practice in basic medical education. London: General Medical Council, 1987.

3 Cruickshank JK, Barritt PW, Besag FMC, Waterhouse N, Goldman LH. Student views on continuous assessment at Birmingham University. Br Med f 1975;iv:265-7.

4 Anonymous. Critical questions, critical incidents, critical answers [Editorial]. Lancet 1988;i:1373-4. 